EXTENDED REPORT

\title{
Retinal vessel wall signs and the 5 year incidence of age related maculopathy: the Blue Mountains Eye Study
}

\author{
J J Wang, P Mitchell, E Rochtchina, A G Tan, T Y Wong, R Klein
}

Br J Ophthalmol 2004;88:104-109

See end of article for authors' affiliations

Correspondence to:

Jie Jin Wang, PhD, Centre

for Vision Research,

Department of

Ophthalmology, University

of Sydney, Westmead

Hospital, Hawkesbury

Road, Westmead, NSW

Australia, 2145;

jiejin_wang@wmi.usyd.
edu.au

Accepted for publication 5 May 2003

\begin{abstract}
Aims: To assess whether retinal arteriolar wall changes (focal narrowing and arteriovenous nicking) are associated with an increased 5 year risk of age related maculopathy (ARM).

Methods: The Blue Mountains Eye Study examined 3654 residents aged 49+ years living in a defined area, during 1992-4 (82.4\% participation). After 5 years, 2335 surviving participants $(75.1 \%)$ were reexamined during 1997-9. Retinal photographs were graded using the Wisconsin ARM grading system. Incident late (neovascular or atrophic) or early stage ARM was defined using a side by side grading method. Focal arteriolar narrowing (localised constricted arteriolar segments causing a sausage-like appearance), and arteriovenous (AV) nicking (constriction on both sides of the venule where crossed by an arteriole), were graded by comparison with standard photographs. All retinal vessels passing through a circumferential zone 0.5-1.0 disc diameters from the optic disc margin were measured from digitised images. Summarised estimates for central retinal arteriolar equivalent (CRAE) represent an average diameter of arterioles for that eye. Associations were assessed after adjusting for age, sex, smoking, mean arterial blood pressure, and other vascular risk factors.

Results: Of 2314 baseline participants at risk of late stage ARM, either late stage lesion developed in 34 participants (1.5\%). Of 2203 at risk of early stage ARM, this sign developed in 197 participants (8.9\%). Focal arteriolar narrowing was present at baseline in at least one eye of 162 survivors $(6.9 \%)$ and severe AV nicking was present in 187 people (8.1\%). Over 5 years, $4.9 \%$ of subjects with and $1.2 \%$ of those without focal narrowing developed either late stage ARM lesion, age adjusted relative risk (RR) $2.3,95 \%$ confidence interval (CI) 1.0 to 5.1, multivariate adjusted odds ratios (OR) 2.1 (95\% $\mathrm{Cl} 0.9$ to 4.9 ). Similarly, $3.7 \%$ of subjects with and $1.3 \%$ of those without severe AV nicking developed late ARM lesions, age adjusted RR 2.1 (95\% Cl 0.9 to 5.1), multivariate adjusted OR 2.2 (95\% Cl 0.9 to 5.6). Corresponding age adjusted RR and multivariate adjusted OR for development of early stage ARM were $1.4195 \% \mathrm{Cl} 0.9$ to 2.0 ) and $1.3(95 \% \mathrm{Cl} 0.8$ to 2.1$)$ for focal arteriolar narrowing, and $1.6(95 \% \mathrm{Cl} 1.0$ to 2.3 ) and 1.8 (95\% $\mathrm{Cl} 1.1$ to 2.9 ) for severe AV nicking, respectively. No associations between baseline CRAE and 5 year incident late or early stage ARM were found.

Conclusions: Although of borderline statistical significance, the consistent associations found in this study suggest that structural retinal arteriolar changes may either contribute to ARM progression or may share common pathological pathways with ARM.
\end{abstract}

$\mathrm{E}$ vidence from epidemiological studies has suggested associations between atherosclerosis, cardiovascular risk factors, and age related maculopathy $(\mathrm{ARM}) .{ }^{12}$ Relevant risk factors include current smoking, ${ }^{34}$ systemic hypertension, ${ }^{56}$ history of coronary, carotid, and peripheral vascular disease, ${ }^{1}$ serum cholesterol, ${ }^{7}$ dietary fat intake, ${ }^{89}$ and body mass index. ${ }^{10}$ However, among these potential risk factors, only smoking has consistently been associated with ARM.

A recent report from the Beaver Dam Eye Study has provided evidence of an association between blood pressure and the risk of developing early or late stage ARM. ${ }^{6}$ Higher systolic blood pressure and higher pulse pressure at baseline were associated with an increased 10 year incidence of retinal pigment abnormalities and of neovascular ARM. Controlled or uncontrolled hypertension under medication at baseline was associated with a twofold to threefold risk of neovascular ARM in 10 years (multivariate adjusted risk ratios were 2.3 and 3.3, respectively). People whose systolic blood pressure had increased more than $5 \mathrm{~mm} \mathrm{Hg}$ from baseline to the 5 year follow up examination were found to have a threefold risk of incident late stage ARM over the next 5 years, compared with people who had stable systolic blood pressure during the same period. ${ }^{6}$
Overwhelming evidence from recent population based studies has documented a strong relation between elevated blood pressure and retinal microvascular changes. ${ }^{11-16}$ This relation has also been demonstrated in our study population. ${ }^{17} 18$

We previously observed a twofold increased prevalence of late stage ARM lesions in persons with focal retinal arteriolar narrowing or arteriovenous (AV) nicking, after adjusting for age, sex, and smoking (unpublished data). Such findings, particularly retinal vessel narrowing, in eyes presenting with late stage ARM, would not be surprising, as these signs could be expected to occur secondary to retinal atrophy involving the posterior pole. The finding of occasional retinal haemorrhages or microaneurysms could also be expected in the presence of neovascular ARM. With such cross sectional observations, it would not be possible, with any certainty, to know whether the retinal vascular changes preceded or were the result of the late stage ARM.

In view of reported associations between cardiovascular function and subsequent development of ARM, together with limited evidence linking microvascular structural changes to this outcome, we aimed to investigate longitudinal associations between structural arteriolar changes present at base- 
line and the subsequent development of early and late stage ARM.

\section{MATERIALS AND METHODS}

The Blue Mountains Eye Study (BMES) is a population based, longitudinal study of vision and eye disease in an urban population aged 49 years or older, resident in two postcode areas in the Blue Mountains region, west of Sydney, Australia. At baseline, 3654 (82.4\%) of the 4433 eligible residents were examined during 1992-4. Five years later, 543 had died and 2335 of the 3111 surviving participants $(75.1 \%)$ were re-examined during 1997-9.

All participants who attended both baseline and 5 year follow up examinations had a face to face interview conducted and comprehensive eye examinations after pupil dilatation, including stereoscopic retinal photographs (30 degree) taken of the macula and other retinal fields of both eyes, $^{19}$ using a Zeiss FF3 fundus camera (Carl Zeiss, Oberkochen, Germany). Stereoscopic retinal photographs of at least one eye were obtained in $98 \%$ of participants at baseline, and in $99 \%$ of those attending the 5 year follow up examinations. Grading for late and early ARM lesions, including neovascular ARM, geographic atrophy, indistinct soft or reticular drusen and retinal pigmentary abnormalities, followed the Wisconsin Age Related Maculopathy Grading System. ${ }^{20}$ Assessment of incident ARM lesions was described in our 5 year ARM incidence report. ${ }^{21}$ All incident cases were confirmed using a side by side grading method. ${ }^{22}$

\section{Definitions}

Late stage ARM lesions were defined to include geographic atrophy at the macula (regardless of foveal involvement) and neovascular ARM, as described in the International ARM Classification. $^{23}$ Lesions classified as neovascular ARM included serous or haemorrhagic detachment of the RPE or sensory retina, presence of subretinal or sub-RPE haemorrhages or subretinal fibrosis and photocoagulation scars in cases previously documented as having neovascular ARM. Geographic atrophy was defined as a discrete area, at least $175 \mu \mathrm{m}$ in diameter, of retinal depigmentation characterised by a sharp border and presence of visible choroidal vessels. In this report, cases with signs of neovascular ARM and widespread geographic atrophy were classified as positive for both subtypes. All cases with late stage ARM lesions at either examination were adjudicated by two retinal specialists (PM, RK). The incidence of either type of late stage ARM lesion was defined as the appearance at follow up of neovascular AMD or geographic atrophy in eyes without either lesion at baseline.

Early stage ARM was defined as the absence of late stage ARM and presence of either: (1) large (>125 $\mu$ m diameter) indistinct soft or reticular drusen or (2) both large distinct soft drusen and retinal pigmentary abnormalities (hyperpigmentation or hypopigmentation $)^{23}$ within the macular area. ${ }^{20}$ Incident early stage ARM was defined as the appearance at follow up of either indistinct soft or reticular drusen or the co-presence of both distinct soft drusen and retinal pigmentary abnormalities in either eye of those in whom no late or early stage ARM was present at baseline and no late stage ARM was present at follow up. Definitions for incident ARM lesions closely followed the definitions developed by Klein et al for the Beaver Dam Eye Study, 22 modified to use fewer categories for drusen size. ${ }^{21}$

Focal arteriolar narrowing and arteriovenous (AV) nicking were graded from $35 \mathrm{~mm}$ retinal slides of both eyes taken at baseline using a light box (Kelvin rating approximately $6200^{\circ}$ ) and a Donaldson viewer. Only arterioles located at least $1 / 2$ disc diameter away from the optic disc margin were assessed for focal arteriolar narrowing. Standard photographs for retinal vascular changes were selected by a retinal specialist (PM) from the standard photographic set developed for the Modified Airlie House Classification of Diabetic Retinopathy $^{24}$ (Standards 2A, 8A, 10A, and 14) and the Wisconsin Age-related Maculopathy Grading System. ${ }^{20}$ Focal arteriolar narrowing, localised sausage-like constrictions along the course of arterioles, was identified and graded as absent/questionable (none or less severe than the standard photograph) or present (equal to or more severe than the standard). AV nicking (nipping) was graded as present when constriction was evident on both sides of a venule where crossed by an arteriole. AV nicking was graded as absent/ questionable, mild (less than the standard), or severe (equal to or greater than the standard). One grader performed this type of grading. A retinal specialist (PM) provided training and adjudication. Intragrader reliability was assessed; kappa statistics for detecting focal arteriolar narrowing and AV nicking were 0.80 and 0.87 , respectively. Both focal arteriolar narrowing and AV nicking were defined using findings from the worse eye.

A computer assisted grading method with high reproducibility was used to measure retinal vessel width (diameter). ${ }^{25}$ In brief, digitised retinal images of one eye (mainly right eyes) of each participant were displayed using Optimate image library software (version 6.5l; Media Cybernetics, Silver Spring, MD, USA) and "RetinalAnalysis" software (Department of Ophthalmology and Visual Science, University of Wisconsin-Madison, Madison, WI, USA). A digital grid consisting of three concentric circles centred on the optic disc was placed over the image. All vessels greater than $25 \mu \mathrm{m}$ in diameter and completely passing through the region $0.5-1.0$ disc diameters from the optic disc margin were measured. The grader identified the arterioles and venules, with reference to the original photographs, and selected a section of the vessel for measurement. Average arteriolar or venular width (diameter) was calculated using the ParrHubbard formula ${ }^{1426}$ and presented as central retinal arteriolar equivalent (CRAE) or central retinal venular equivalent (CRVE). Generalised retinal arteriolar narrowing was defined as CRAE within the lowest quintile for the population. The Parr-Hubbard formula is:

$$
\mathrm{Wc}=\left(0.87 \mathrm{~W}_{\mathrm{a}}^{2}+1.01 \mathrm{~W}_{\mathrm{b}}^{2}-0.22 \mathrm{~W}_{\mathrm{a}} \mathrm{W}_{\mathrm{b}}-10.73\right)^{1 / 2} \text { for CRAE }
$$

and

$$
\mathrm{W}_{\mathrm{C}}=\left(0.72 \mathrm{~W}_{\mathrm{a}}^{2}+0.91 \mathrm{~W}_{\mathrm{b}}^{2}+450.05\right)^{1 / 2} \text { for CRVE }
$$

where $\mathrm{W}_{\mathrm{c}}$ was calculated as the trunk calibre, and includes calibres from the smallest $\left(\mathrm{W}_{\mathrm{a}}\right)$ to largest branches $\left(\mathrm{W}_{\mathrm{b}}\right){ }^{14}$

Eyes were only considered gradable if all vessels, of width greater than $45 \mu \mathrm{m}$ could be measured accurately. Intragrader and intergrader grading reliability of this method was assessed previously, ${ }^{25}$ with quadratic weighted kappa 0.85 (CRAE) and 0.90 (CRVE) for intergrader reliability and between $0.80-0.93$ and $0.80-0.92$ for intragrader reliability in grader 1 and 2 respectively. Good correlation in measurement between right and left eyes was also found. ${ }^{27}$

At baseline, blood pressure (BP) was measured after participants had been comfortably seated for at least 5 minutes. A single measure of systolic and diastolic blood pressures (SBP, DBP) using a mercury sphygmomanometer was recorded from the first and fifth Korotkoff sounds. Mean arterial blood pressure (MABP) was calculated as 0.33 (SBP) +0.67 (DBP).

Statistical Analysis System (SAS, SAS Institute, Cary, NC, USA), was used for statistical analyses, which were performed using each of the following incident ARM lesions as a dependent variable: neovascular ARM, geographic 
atrophy, late stage ARM lesion, early stage ARM, retinal pigmentary abnormality and indistinct soft/reticular drusen. Age adjusted relative risks (RR) were calculated using the Cochran-Mantel-Haenszel method, over 10 year age group strata. The relation between incident ARM stages or lesions and each type of retinal arteriolar change at baseline was further assessed using logistic regression models controlling for potential confounders, including age (continuous), sex (dichotomous), smoking (trichotomous: never, past and current) and mean arteriolar blood pressure (continuous) measured at baseline. Generalised estimating equation (GEE) models $^{28-30}$ were used to assess eye specific associations between focal retinal arteriolar narrowing, AV nicking, and incident late or early stage ARM. Adjusted relative risks (RR), odds ratios (OR), and 95\% confidence intervals (CI) are presented.

\section{RESULTS}

In this older cohort of 2335 participants, 21 were found to have late stage ARM at baseline, thus were not considered as at risk of developing late stage ARM. Among the 2314 at risk, 23 participants $(1.0 \%)$ developed incident neovascular ARM, $17(0.7 \%)$ developed incident GA, and 34 (1.5\%) developed either late stage ARM lesions over 5 years (six developed both incident neovascular ARM and GA). After excluding those with late or early stage ARM at baseline or with late stage ARM at 5 year follow up, 2203 those were considered at risk of developing early stage ARM. Among this group, 197 (8.9\%) developed early stage ARM over 5 years; 177 of 2005 participants $(8.8 \%)$ developed incident retinal pigmentary abnormalities, and 114 of 2148 (5.3\%) developed incident soft indistinct or reticular drusen.

Table 1 shows the relation between focal arteriolar narrowing, AV nicking and ARM risk factors collected at baseline in the 2335 participants. Age and blood pressure were significantly associated with both focal narrowing and AV nicking. Body mass index was significantly associated with AV nicking but not with focal narrowing.

At baseline, 162 participants $(7.0 \%)$ in the surviving cohort were found to have focal arteriolar narrowing in at least one eye, of whom eight (4.9\%) developed either neovascular ARM or geographic atrophy over 5 years, compared to 26 participants $(1.2 \%)$ without focal narrowing. The age adjusted relative risk for development of late stage ARM lesions was 2.3 (95\% CI 1.0 to 5.1 ) for those with compared to those without focal arteriolar narrowing (table 2). The age adjusted relative risk for development of early stage ARM in persons with focal arteriolar narrowing was 1.4 (95\% CI 0.9 to 2.0 ). Further adjustment for sex, smoking, and mean arterial blood pressure did not alter these associations appreciably (OR 2.1, 95\% CI 0.9 to 4.9 for late stage ARM lesions and OR $1.3,95 \%$ CI 0.8 to 2.1 for early stage ARM).

At baseline, $902(39.0 \%)$ and 187 (8.1\%) participants had mild and severe AV nicking, respectively. Of those with severe AV nicking, seven (3.7\%) developed either late stage ARM lesion over 5 years, compared with 16 (1.3\%) without AV nicking, age adjusted relative risk 2.1 (95\% CI 0.9 to 5.1 ), as shown in table 3 . The age adjusted relative risk of developing early stage ARM was 1.6 (95\% CI 1.0 to 2.3 ). Further adjustment for sex, smoking, and mean arterial blood pressure did not alter the association appreciably (OR 2.2, $95 \%$ CI 0.9 to 5.7 for late stage ARM lesions and OR 1.8, $95 \%$ CI 1.1 to 3.0 for early stage ARM).

Eye specific findings on the relation between focal arteriolar narrowing, AV nicking, and incident ARM support the subject specific (worse eye) findings reported above. Table 4 demonstrates associations between incident early or late stage ARM and structural arteriolar signs based on analysis of data from two eyes using a GEE model, showing significantly increased odds for incident early stage ARM in eyes with these retinal vessel wall changes.

No significant association nor trend of association, was found between baseline CRAE and the 5 year incidence of late or early stage ARM (table 5).

Adjusting for current or ever use at baseline of antihypertensive medication, or $\beta$ blockers specifically, or hypertension status, instead of mean arterial blood pressure in the models did not alter these associations substantially (data not shown). Additional adjustment for body mass index and serum lipids (cholesterol or triglyceride) in the multivariate model containing age, sex, smoking, and MBP did not substantially alter the association (data not shown).

\section{DISCUSSION}

Findings from our study suggest a possible association between retinal vessel changes (focal arteriolar narrowing and AV nicking) and the subsequent development of either late or early stage ARM. Incident late stage ARM lesions were seen twice as frequently in those with than without retinal vessel signs, while incident early stage ARM was $60 \%$ more

Table 1 Retinal vascular wall signs and age related maculopathy (ARM) risk factors in the Blue Mountains Eye Study population

\begin{tabular}{|c|c|c|c|c|c|c|c|c|}
\hline \multirow[b]{2}{*}{ ARM risk factor } & \multicolumn{3}{|c|}{ Focal retinal arteriolar narrowing } & \multicolumn{5}{|c|}{ Arteriovenous nicking } \\
\hline & Absent & Present & p Value & Absent & Mild & $\mathrm{p}$ Value & Moderate/severe & $\mathrm{p}$ Value \\
\hline Mean age (years) & 64 & 70.5 & $<0.0001$ & 63.4 & 65.6 & $<0.0001^{*}$ & 66.7 & $<0.0001^{*}$ \\
\hline Systolic blood pressure $(\mathrm{mm} \mathrm{Hg})$ & 144.3 & 158.4 & $<0.0001$ & 143.3 & 147.0 & $<0.0001^{*}$ & 151.2 & $<0.0001^{*}$ \\
\hline Diastolic blood pressure (mm Hg) & 83.1 & 89.2 & $<0.0001$ & 83.1 & 83.9 & $0.044^{*}$ & 85.7 & $<0.001^{*}$ \\
\hline Mean arterial blood pressure $(\mathrm{mm} \mathrm{Hg})$ & 103.3 & 112.0 & $<0.0001$ & 103.0 & 104.7 & $<0.001^{*}$ & 107.3 & $<0.0001^{*}$ \\
\hline Mean body mass index & 26.2 & 26.6 & 0.26 & 26.0 & 26.6 & $0.0014^{*}$ & 27.0 & $0.0038^{*}$ \\
\hline Age group (\%) & & & $<0.0001 \dagger$ & & & & & $<0.0001 \uparrow$ \\
\hline$<60$ & 97.5 & 2.5 & & 63.2 & 31.6 & & 5.3 & \\
\hline $60-69$ & 93.9 & 6.1 & & 50.0 & 42.1 & & 7.9 & \\
\hline 70-79 & 88.6 & 11.4 & & 47.2 & 41.0 & & 11.8 & \\
\hline $80+$ & 77.1 & 22.9 & & 37.3 & 53.4 & & 9.3 & \\
\hline $\operatorname{Sex}(\%)$ & & & 0.37 & & & & & 0.58 \\
\hline Women & 92.5 & 7.5 & & 51.9 & 39.7 & & 8.4 & \\
\hline Men & 93.5 & 6.6 & & 53.9 & 38.4 & & 7.7 & \\
\hline Smoking status (\%) & & & $0.29 \dagger$ & & & & & $0.61 \dagger$ \\
\hline Never & 92.5 & 7.5 & & 53.3 & 38.4 & & 8.3 & \\
\hline Past & 92.9 & 7.1 & & 52.7 & 39.7 & & 7.6 & \\
\hline Current & 94.4 & 5.6 & & 50.8 & 40.6 & & 8.6 & \\
\hline
\end{tabular}

${ }^{*} t$ Test for comparison between absent and mild or moderate to severe groups.

†Mantel-Haenszel $\chi^{2}$ test for trend. 
Table 2 Five year incidence of age related maculopathy (ARM) lesions by presence of focal arteriolar narrowing at baseline

\begin{tabular}{|c|c|c|c|c|c|c|}
\hline ARM lesion & $\begin{array}{l}\text { Focal arteriolar } \\
\text { narrowing }\end{array}$ & No at risk & No affected (\%) & $\begin{array}{l}\text { Age adjusted relative } \\
\text { risk* }^{*}(95 \% \mathrm{CI})\end{array}$ & $\begin{array}{l}\text { Age/sex adjusted } \\
\text { odds ratiot }(95 \% \mathrm{Cl})\end{array}$ & $\begin{array}{l}\text { Age/sex/smoking/mean } \\
\text { arterial } \mathrm{BP} \text { adjusted odds } \\
\text { ratio† }(95 \% \mathrm{CI})\end{array}$ \\
\hline \multicolumn{7}{|l|}{ Late stage ARM } \\
\hline \multirow{2}{*}{ Neovascular AMD } & absent & 2152 & $18(0.8)$ & 1.0 & 1.0 & 1.0 \\
\hline & present & 162 & $5(3.1)$ & $2.1(0.8$ to 5.8$)$ & $1.8(0.6$ to 5.2$)$ & $2.0(0.7$ to 6.0$)$ \\
\hline \multirow[t]{2}{*}{ Geographic atrophy } & absent & 2152 & $13(0.6)$ & 1.0 & 1.0 & 1.0 \\
\hline & present & 162 & $4(2.5)$ & $2.2(0.7$ to 7.0$)$ & $1.9(0.6$ to 6.3$)$ & $1.8(0.5$ to 6.1$)$ \\
\hline \multirow[t]{2}{*}{ Either late stage ARM lesion } & absent & 2152 & $26(1.2)$ & 1.0 & 1.0 & 1.0 \\
\hline & present & 162 & $8(4.9)$ & 2.3 (1.0 to 5.1$)$ & $2.0(0.9$ to 4.7$)$ & $2.1(0.9$ to 4.9$)$ \\
\hline \multicolumn{7}{|l|}{ Early stage ARM lesions } \\
\hline \multirow[t]{2}{*}{ Pigment abnormality } & absent & 1880 & $161(8.6)$ & 1.0 & 1.0 & 1.0 \\
\hline & present & 125 & $16(12.8)$ & $1.2(0.7$ to 1.9$)$ & $1.1(0.6$ to 1.9$)$ & $1.1(0.6$ to 2.0$)$ \\
\hline \multirow[t]{2}{*}{ Indistinct soft/reticular drusen } & absent & 2011 & $102(5.1)$ & 1.0 & 1.0 & 1.0 \\
\hline & present & 137 & $12(8.8)$ & $1.1(0.7$ to 2.0$)$ & $1.0(0.5$ to 2.0$)$ & $1.0(0.5$ to 1.9$)$ \\
\hline \multirow[t]{2}{*}{ Early stage ARM } & absent & 2061 & $174(8.4)$ & 1.0 & 1.0 & $1.0^{\circ}$ \\
\hline & present & 142 & 23 (16.2) & $1.4(0.9$ to 2.0$)$ & $1.3(0.8$ to 2.2$)$ & $1.3(0.8$ to 2.1$)$ \\
\hline
\end{tabular}

*Mantel-Haenszel estimates.

†Logistic regression estimates.

likely, after adjusting for age, sex, smoking, and mean arterial blood pressure. Although only a few estimates were of borderline statistical significance, the majority were nonsignificant. Our findings were generally consistent within the study and are broadly in keeping with findings from the Rotterdam Study, ${ }^{1}$ the Beaver Dam Eye Study, ${ }^{61}$ and the Atherosclerosis Risk in Communities (ARIC) Study. ${ }^{32}$

In a nested case-control study within the Rotterdam Study baseline survey, people aged younger than 85 years with carotid plaques were substantially more likely to have ARM. ${ }^{1}$ In the ARIC study population, retinal arteriolar focal narrowing was significantly associated with prevalent retinal pigment epithelial depigmentation. ${ }^{32}$ In the 5 year follow up examination of the Beaver Dam Eye Study, baseline high pulse pressure, but not hypertension, was found to be significantly associated with 5 year incident retinal pigmentary abnormality and neovascular ARM. ${ }^{31}$ However, at the 10 year follow up examination of the same cohort, in addition to systolic blood pressure and pulse pressure, baseline hypertension was found to be significantly associated with the 10 year incidence of neovascular ARM. ${ }^{6}$
In contrast with previous studies of the relation between hypertension/atherosclerosis and ARM, the current study was conducted to assess the relation between ARM and structural changes in retinal arterioles that are likely to reflect microvascular damage from long standing hypertension. One strength of this study is that the retinal vessel changes were documented from baseline retinal photographs, before the development of either early or late stage ARM. Blood pressure levels may fluctuate over time, often in relation to current treatment, whereas structural arteriolar signs may be a more stable indication of the severity of hypertensive damage. Findings from this and three other study populations $^{1632}$ consistently suggest a possibility of an association between vascular disease and ARM. Data from the Beaver Dam Study also suggest that there could be a relatively long term time lapse between the occurrence of vascular diseases and the development of ARM. ${ }^{6}{ }^{31}$

In our study, the grading of focal arteriolar narrowing and $\mathrm{AV}$ nicking was masked to participants' identity and to their blood pressure status, but required subjective judgment from graders using reference to standard retinal photographs. In our study population, we have observed a significant

Table 3 Five year incidence of age related maculopathy (ARM) lesions by presence of arteriovenous nicking at baseline

\begin{tabular}{|c|c|c|c|c|c|c|}
\hline Incident ARM lesion & AV nicking & No at risk & No affected (\%) & $\begin{array}{l}\text { Age adjusted } \\
\text { relative risk* } 195 \% \\
\mathrm{Cl})\end{array}$ & $\begin{array}{l}\text { Age/sex adjusted odds } \\
\text { ratiot }(95 \% \mathrm{Cl})\end{array}$ & $\begin{array}{l}\text { Age/sex/smoking/mean } \\
\text { BP adjusted odds ratio† } \\
(95 \% \mathrm{Cl})\end{array}$ \\
\hline \multicolumn{7}{|l|}{ Late stage ARM } \\
\hline \multirow[t]{3}{*}{ Neovascular AMD } & absent & 1225 & $11(0.9)$ & 1.0 & 1.0 & 1.0 \\
\hline & mild & 902 & $8(0.9)$ & $0.8(0.3$ to 2.1$)$ & $0.7(0.3$ to 1.9$)$ & $0.8(0.3$ to 2.0$)$ \\
\hline & severe & 187 & $4(2.1)$ & $1.8(0.5$ to 5.7$)$ & $1.7(0.5$ to 5.6$)$ & $1.9(0.6$ to 6.2$)$ \\
\hline \multirow[t]{3}{*}{ Geographic atrophy } & absent & 1225 & $8(0.7)$ & 1.0 & 1.0 & 1.0 \\
\hline & mild & 902 & $5(0.6)$ & $0.7(0.2$ to 2.1$)$ & $0.6(0.2$ to 1.9$)$ & $0.6(0.2$ to 1.9$)$ \\
\hline & severe & 187 & $4(2.1)$ & $2.3(0.7$ to 7.6$)$ & $2.4(0.7$ to 8.2$)$ & $2.5(0.7$ to 8.7$)$ \\
\hline \multirow[t]{3}{*}{ Either late stage ARM lesion } & absent & 1225 & $16(1.3)$ & 1.0 & 1.0 & 1.0 \\
\hline & mild & 902 & $11(1.2)$ & $0.7(0.3$ to 1.6$)$ & $0.7(0.3$ to 1.5$)$ & $0.7(0.3$ to 1.5$)$ \\
\hline & severe & 187 & $7(3.7)$ & $2.1(0.9$ to 5.1$)$ & $2.1(0.8$ to 5.4$)$ & $2.2(0.9$ to 5.7$)$ \\
\hline \multicolumn{7}{|l|}{ Early stage ARM lesions } \\
\hline \multirow[t]{3}{*}{ Pigment abnormality } & absent & 1076 & $87(8.1)$ & 1.0 & 1.0 & 1.0 \\
\hline & mild & 775 & $74(9.6)$ & $1.1(0.8$ to 1.5$)$ & $1.1(0.8$ to 1.5$)$ & $1.1(0.8$ to 1.5$)$ \\
\hline & severe & 154 & $16(10.4)$ & $1.1(0.7$ to 1.9$)$ & $1.1(0.7$ to 2.0$)$ & $1.2(0.7$ to 2.0$)$ \\
\hline \multirow[t]{3}{*}{ Indistinct soft/reticular drusen } & absent & 1154 & $52(4.5)$ & 1.0 & 1.0 & 1.0 \\
\hline & mild & 828 & $47(5.7)$ & $1.2(0.8$ to 1.6$)$ & $1.1(0.7$ to 1.6$)$ & $1.0(0.7$ to 1.6$)$ \\
\hline & severe & 166 & $15(9.0)$ & $1.5(0.9$ to 2.6$)$ & $1.7(0.9$ to 3.1$)$ & $1.7(0.9$ to 3.1$)$ \\
\hline \multirow[t]{3}{*}{ Early stage ARM } & absent & 1180 & $88(7.5)$ & 1.0 & 1.0 & 1.0 \\
\hline & mild & 850 & $83(9.8)$ & $1.2(0.9$ to 1.6$)$ & $1.2(0.8$ to 1.6$)$ & $1.1(0.8$ to 1.6$)$ \\
\hline & severe & 173 & $26(15.0)$ & 1.6 (1.0 to 2.3 ) & $1.8(1.1$ to 3.0$)$ & 1.8 (1.1 to 2.9$)$ \\
\hline
\end{tabular}


Table 4 Eye specific assessment of the relation between retinal vessel signs and incident late stage age related maculopathy (ARM) lesions or early stage ARM

\begin{tabular}{ll}
\hline Retinal vessel wall sign & $\begin{array}{l}\text { Age/sex/smoking/mean } \\
\text { BP adjusted odds ratio* } \\
\text { (95\% Cl) }\end{array}$ \\
\hline $\begin{array}{l}\text { Incidence of either late stage ARM lesion } \\
\text { Focal retinal arteriolar narrowing }\end{array}$ & $1.9(0.8$ to 4.7$)$ \\
Mild AV nicking & $0.8(0.4$ to 1.5$)$ \\
$\begin{array}{l}\text { Severe AV nicking } \\
\text { Incident early stage ARM }\end{array}$ & $1.7(0.6$ to 5.0$)$ \\
Focal retinal arteriolar narrowing & $2.0(1.2$ to 3.2$)$ \\
Mild AV nicking & $1.1(0.8$ to 1.4$)$ \\
Severe AV nicking & $1.7(1.0$ to 2.8$)$ \\
\hline
\end{tabular}

*Estimated using generalised estimating equation (GEE) models.

association between blood pressure and either focal arteriolar narrowing or AV nicking, after adjusting for age, sex, smoking, body mass index, blood glucose, and serum lipids (unpublished data). Such retinal vessel changes could have been indicators of microvascular damage resulting from long term elevated blood pressure. ${ }^{14}$

Prolonged filling of the choroidal capillaries has been demonstrated in $\mathrm{ARM}^{33}$ so it is possible that the retinal vasculature also shares perfusion problems in late stage ARM cases. A model has proposed that choroidal haemodynamic factors could increase resistance of the choroidal circulation, a state that could be mirrored in the retinal circulation. ${ }^{34}$ Snow and Seddon recently reviewed epidemiological research regarding ARM risk factors associated with cardiovascular disease and concluded that the evidence overall suggested a mild to moderate association between elevated blood pressure and late stage ARM. ${ }^{2}$ This relation was confirmed in a later report of a large case-control study ${ }^{5}$ and, more strongly, in the 10 year Beaver Dam Eye Study data. ${ }^{6}$

We used a computer assisted, semiautomatic method to assess generalised narrowing of retinal arterioles, which was shown to have a high intergrader and intragrader reproducibility. ${ }^{25}$ We also observed a significant negative trend between increasing mean arterial blood pressure and decreasing CRAE (an estimate of the average retinal arteriolar diameter), after adjusting for age, sex, smoking, body mass index, and blood glucose. ${ }^{18}$ However, we found no trend of association between CRAE quintiles and 5 year incident early or late stage ARM. Focal narrowing may represent a more severe vascular lesion than the lowest CRAE (or arteriole to venule ratio) quintile, representing generalised narrowing. In the ARIC study, AV nicking and focal narrowing were stronger predictors of incident stroke than measures of generalised narrowing. ${ }^{35}$ Alternatively, as we used data from the worse eye to define focal arteriolar narrowing or AV nicking, but used data from one eye for the CRAE measures, it is possible that data from two eyes would better reflect microvascular damage to an individual. However, given the high correlations (0.75 to 0.80) found between the two eyes in this population, ${ }^{27}$ this seems unlikely as the average retinal arteriolar diameter (CRAE) estimated from one eye is very similar to that from the average of two eyes.

A major limitation of our study is the relatively small number of incident late stage ARM cases, with insufficient study power to examine these associations in detail. However, we found consistently increased odds, with lower confidence limits at or close to 1.0 for focal narrowing and AV nicking. Both retinal arteriolar changes and ARM are strongly age related. It is possible that we could not fully adjust for the effects of age, by the inclusion of age as a continuous variable in the statistical models. As we were able to re-examine only $75 \%$ of the surviving cohort, selection or survival bias could have been introduced. Given that participants who had died or who did not return for the 5 year follow up examination could have been more likely to develop ARM, ${ }^{21}$ any bias arising from this would most likely be towards the null. The finding of a positive association between retinal vessel wall signs and incident ARM is not necessarily causal, as it could be due to sharing of similar risk factors (such as hypertension), or common antecedents in the pathological pathways for these two conditions. ${ }^{2}$

In conclusion, the associations found between structural retinal vessel wall signs (focal arteriolar narrowing and AV nipping) and incident late or early stage ARM in the Blue Mountains Eye Study provide support for the concept that vascular factors may contribute to the pathogenesis of ARM. Many associations, however, were either borderline or not statistically significant after adjusting for other known ARM risk factors, including smoking and mean arterial blood pressure, possibly because of insufficient study power. Although we cannot exclude the possibility of incomplete adjustment for potential confounders, our findings are consistent with findings from a number of other population based studies. Longer term follow up of our population and data pooling from other studies may help to clarify this relation.

Table 5 Five year incidence of age related maculopathy (ARM) lesions by presence of generalised arteriolar narrowing (lower quintiles of central retinal arteriolar equivalent, CRAE) at baseline

\begin{tabular}{|c|c|c|c|c|c|c|}
\hline \multirow[b]{2}{*}{ Incident ARM lesion } & \multicolumn{3}{|c|}{ Central retinal arteriolar equivalent $(\mu \mathrm{m})$} & \multirow{2}{*}{$\begin{array}{l}\text { Age adjusted relative } \\
\text { risk }^{*}(95 \% \mathrm{Cl})\end{array}$} & \multirow{2}{*}{$\begin{array}{l}\text { Age/sex adjusted odds } \\
\text { ratiot }(95 \% \mathrm{Cl})\end{array}$} & \multirow{2}{*}{$\begin{array}{l}\text { Age/sex/smoking/ } \\
\text { mean BP Adjusted } \\
\text { odds ratio† }(95 \% \mathrm{Cl})\end{array}$} \\
\hline & Quintile & mean (SD) & No affected (\%) & & & \\
\hline \multicolumn{7}{|c|}{ Either late stage ARM lesion } \\
\hline & 5 th & $211.9(8.9)$ & $3(0.7)$ & 1.0 & 1.0 & 1.0 \\
\hline & 4 th & $196.6(2.9)$ & $10(2.2)$ & $3.0(0.9$ to 10.4$)$ & $2.9(0.8$ to 10.7$)$ & $3.1(0.8$ to 11.4$)$ \\
\hline & $3 r d$ & $187.1(2.7)$ & $7(1.6)$ & $2.0(0.5$ to 8.1$)$ & $1.7(0.4$ to 6.9$)$ & $1.8(0.5$ to 7.3$)$ \\
\hline & 2nd & $177.7(3.0)$ & $5(1.2)$ & $1.3(0.3$ to 6.1$)$ & $1.1(0.3$ to 4.9$)$ & $1.2(0.3$ to 5.2$)$ \\
\hline & lst & $162.1(9.8)$ & $6(1.4)$ & $1.4(0.3$ to 6.9$)$ & $1.2(0.3$ to 5.1$)$ & $1.4(0.3$ to 5.7$)$ \\
\hline \multicolumn{7}{|l|}{ Early stage ARM } \\
\hline & 5 th & $211.9(8.9)$ & $37(8.7)$ & 1.0 & 1.0 & 1.0 \\
\hline & 4 th & $196.6(2.9)$ & $40(9.4)$ & $1.0(0.7$ to 1.6$)$ & $1.0(0.6$ to 1.6$)$ & $1.0(0.6$ to 1.6$)$ \\
\hline & $3 r d$ & $187.1(2.7)$ & $38(9.1)$ & $1.0(0.6$ to 1.5$)$ & $0.9(0.6$ to 1.5$)$ & $0.9(0.6$ to 1.5$)$ \\
\hline & 2nd & $177.7(3.0)$ & $30(7.3)$ & $0.7(0.4$ to 1.1$)$ & $0.6(0.4$ to 1.1$)$ & $0.6(0.4$ to 1.1$)$ \\
\hline & $1 \mathrm{st}$ & $162.1(9.8)$ & $39(9.5)$ & $0.8(0.5$ to 1.3$)$ & $0.8(0.5$ to 1.3$)$ & 0.8 (0.5 to 1.3$)$ \\
\hline
\end{tabular}




\section{ACKNOWLEDGEMENT}

Supported by the Australian National Health and Medical Research Council, Canberra Australia (grants 153948, 211069) and US grants to Klein and co-workers (NIH EY06594 and HL 59259).

\section{Authors' affiliations}

J J Wang, P Mitchell, E Rochtchina, A G Tan, Centre for Vision

Research, Department of Ophthalmology and the Westmead

Millennium, the University of Sydney, Australia

T Y Wong, Singapore Eye Research Institute and National University of Singapore, Singapore

R Klein, Department of Ophthalmology and Visual Sciences, University of Wisconsin-Madison, WI, USA

This paper was presented at the 1st SERI-ARVO Meeting in Singapore 2003.

\section{REFERENCES}

1 Vingerling JR, Dielemans I, Bots ML, et al. Age-related macular degeneration is associated with atherosclerosis. The Rotterdam Study. Am J Epidemiol 1995; 142:404-9

2 Snow KK, Seddon JM. Do age-related macular degeneration and cardiovascular disease share common antecedents? Ophthalmic Epidemiol 1999:6:125-43.

3 Smith W, Assink J, Klein R, et al. Risk factors for age-related macular degeneration: pooled findings from three continents. Ophthalmology 2001;108:697-704.

4 Mitchell P, Wang JJ, Smith W, et al. Smoking and the 5-year incidence of age-related maculopathy: the Blue Mountains Eye Study. Arch Ophthalmol 2002; 120:1357-63

5 Hyman L, Schachat $A P, H e Q$, et al. Hypertension, cardiovascular disease, and age-related macular degeneration. Age-Related Macular Degeneration Risk Factors Study Group. Arch Ophthalmol 2000;118:351-8.

6 Klein R, Klein BEK, Tomany SC, et al. The association of cardiovascular disease with the long-term incidence of age-related maculopathy. The Beaver Dam Eye Study. Ophthalmology 2003:1 10:1273-80.

7 Klein R, Klein BE, Franke T. The relationship of cardiovascular disease and its risk factors to age-related maculopathy. The Beaver Dam Eye Study. Ophthalmology 1993;100:406-14.

8 Mares Perlman JA, Brady WE, Klein R, et al. Dietary fat and age-related maculopathy. Arch Ophthalmol 1995;113:743-8.

9 Smith W, Mitchell P, Leeder SR. Dietary fat and fish intake and age-related maculopathy. Arch Ophthalmol 2000;1 18:401-4.

10 Schaumberg DA, Christen WG, Hankinson SE, et al. Body mass index and the incidence of visually significant age-related maculopathy in men. Arch Ophthalmol 2001;119:1259-65.

11 Klein R, Klein BE, Moss SE, et al. Blood pressure, hypertension and retinopathy in a population. Trans Am Ophthalmol Soc 1993;91:207-22.

12 Klein R, Klein BE, Moss SE, et al. Hypertension and retinopathy, arteriolar narrowing, and arteriovenous nicking in a population. Arch Ophthalmol 1994:112:92-8.

13 Klein R, Klein BE, Moss SE. The relation of systemic hypertension to changes in the retinal vasculature: the Beaver Dam Eye Study. Trans Am Ophthalmol Soc 1997:95:329-48

14 Hubbard LD, Brothers RJ, King WN, et al. Methods for evaluation of retina microvascular abnormalities associated with hypertension/sclerosis in the
Atherosclerosis Risk in Communities Study. Ophthalmology 1999; 106:2269-80.

15 Sharrett AR, Hubbard LD, Cooper LS, et al. Retinal arteriolar diameters and elevated blood pressure: the Atherosclerosis Risk in Communities Study. Am J Epidemiol 1999;150:263-70.

16 Wong TY, Hubbard LD, Klein R, et al. Retinal microvascular abnormalities and blood pressure in older people: the Cardiovascular Health Study. Br J Ophthalmol 2002;86:1007-13.

17 Yu T, Mitchell P, Berry G, et al. Retinopathy in older persons without diabetes and its relationship to hypertension. Arch Ophthalmol 1998;116:83-9.

18 Leung H, Wang JJ, Rochtchina E, et al. Relationships between age, blood pressure and retinal vessel diameters in an older population. Invest Ophthalmol Vis Sci 2003:44:900-4

19 Mitchell P, Smith W, Attebo K, et al. Prevalence of age-related maculopathy in Australia. The Blue Mountains Eye Study. Ophthalmology 1995; 102:1450-60.

20 Klein R, Davis M, Magli Y, et al. The Wisconsin age-related maculopathy grading system. Ophthalmology 1991;98:1128-34.

21 Mitchell P, Wang JJ, Foran S, et al. Five-year incidence of age-related maculopathy lesions: The Blue Mountains Eye Study. Ophthalmology 2002;109: 1092-7.

22 Klein $\mathbf{R}$, Klein BE, Jensen SC, et al. The five-year incidence and progression of age-related maculopathy: the Beaver Dam Eye Study. Ophthalmology 1997:104:7-21.

23 Bird AC, Bressler NM, Bressler SB, et al. An international classification and grading system for age-related maculopathy and age-related macular degeneration. The International ARM Epidemiological Study Group. Surv Ophthalmol 1995;39:367-74.

24 Diabetic Retinopathy Study Research Group. DRS Report Number 7: A modification of the Airlie House classification of diabetic retinopathy. Invest Ophthalmol Vis Sci 1981;21:210-26.

25 Sherry LM, Wang JJ, Rochtchina E, et al. Reliability of computer-assisted retinal vessel measurementin a population. Clin Exp Ophthalmol 2002;30:179-82

26 Parr JC, Spears GF. General caliber of the retinal arteries expressed as the equivalent width of the central retinal artery. Am J Ophthalmol 1974:77:472-7.

27 Leung $\mathrm{H}$, Wang JJ, Rochtchina $\mathrm{E}$, et al. Computer-assisted retinal vessel measurement in an older population: Correlation between right and left eyes. Clin Exp Ophthalmol 2003;31:326-30.

28 Zeger SL, Liang KY, Albert PS. Models for longitudinal data: a generalized estimating equation approach. Biometrics 1988;44:1049-60.

29 Glynn RJ, Rosner B. Accounting for the correlation between fellow eyes in regression analysis. Arch Ophthalmol 1992;110:381-7.

30 Katz J, Zeger S, Liang KY. Appropriate statistical methods to account for similarities in binary outcomes between fellow eyes. Invest Ophthalmol Vis Sci 1994:35:2461-5.

31 Klein $\mathbf{R}$, Klein BE, Jensen SC. The relation of cardiovascular disease and its risk factors to the 5-year incidence of age-related maculopathy: the Beaver Dam Eye Study. Ophthalmology 1997;104:1804-12.

32 Klein R, Clegg L, Cooper LS, et al. Prevalence of age-related maculopathy in the Atherosclerosis Risk in Communities Study. Arch Ophthalmol 1999; 117:1203-10.

33 Pauleikhoff D, Chen JC, Chisholm IH, et al. Choroidal perfusion abnormality with age-related Bruch's membrane change. Am J Ophthalmol 1990; 109:211-7.

34 Friedman E. A hemodynamic model of the pathogenesis of age-related macular degeneration [editorial]. Am J Ophthalmol 1997; 124:677-82.

35 Wong TY, Klein R, Couper DJ, et al. Retinal microvascular abnormalities and incident stroke: the Atherosclerosis Risk in Communities Study. Lancet 2001;358:1134-40. 